\title{
Analysis of Program Structures, Content and Functional Roles of Republic Islamic of Iran Broadcast Sport TV Channel
}

\author{
Reza Sadeghi ${ }^{1}$, Ali Mohammad Safania ${ }^{2}$ and Hamid Ghasemi ${ }^{3}$ \\ ${ }^{1}$ Department, Physical Education Faculty, Shomal University, Amol, Mazandaran, Iran \\ ${ }^{2}$ Department of Sport Management, Islamic Azad University, \\ Science and Research Branch, Tehran, Iran \\ ${ }^{3}$ Deaprtment of Sport Management, Physical Education Faculty, \\ Payam Noor University, Alborz, Iran. \\ DOI: http://dx.doi.org/10.13005/bbra/1954
}

(Received: 19 September 2015; accepted: 03 November 2015)

\begin{abstract}
The aim of this research was the analysis of the structure, content and the functional roles of IRIB sport TV channel. This study was an applied and content analysis research. The tools that data collected by it was a researcher made coding sheet that analyzed contents and structures of sport channels. Its objectivity coefficient confirmed by kappa coefficient $0 / 89$. Statistical population of this study was Iran sport TV. Statistical sample was selected among 13 week. The method of selection was cluster - random and the size of sample considered 14 days since 21 March until 5 April 2015. The descriptive statistics like percentages and charts is used to describe the variables. Also the Xi2 test is used to analyze the hypothesis. The results showed that there was a significant difference in the level of $(p<0.01)$ in the variables of sex, functional roles, four components of sport and the production field of the sport programs but in the production axis of the sport program variable was not observed a significant difference among the programs of sport channel.
\end{abstract}

Key words: conductor, sport, program, TV, channel.

This present era is the age of communication and information and the world is converting to a global village. Here the role of the mass media especially television is unavoidably in facilitating the transfer of information. The media diversity, be active, selectivity and the entertainment aspect of group media has caused to accept and the increased use of them in the society. Media is the most components of communication. The selection and proper use of the media has an important role in achieving the goals of mass communication. Media are a form of mass communication and usually are included

\footnotetext{
* To whom all correspondence should be addressed. Mob.:+989127430839;

E-mail: R.Sadeghi1989@gmail.com
}

television, publications, radio and even cinema. Media have the direct effect on the values and norms of society because its domain covers the countless people. McLuhan in the communications system knows the means of communication as the source of changes. Television has specific skill in the performance and value to events.

Today, television is building structure and characteristics of their own as a visual media, the structure which causes finds a certain attention and charm and is raised as pervasive media of technology era.

Among all of the used tools to achieve domination none is not imported in the sport field over group media. It is obvious that sport in the media it is nothing that like power, politics and ideology categories is treated with it, but is a 
phenomenon for doing skillfully, appealing and above all leisure and fun activities.

In the most countries people spend their time in a room between 10-25 hours in a week which in it the television is on. The relationship between the sport and broadcasting is a bilateral media coverage. Each of the sport fields and its media player have mutual dependence and interaction on each other. The TV channels is targeted the various sectors of society. They benefit most from the sport as a tool for increasing of audiences. The channels which are targeted higher socioeconomic groups may be turn to the sports peculiar of these classes like rugby, golf and cricket. They know that some special sporting events can draw the large target population to television. The qualitative research of media-sport typically begins of a general question about the relationship between production and consumption of media content. For example, Lowes is began a study on the sport section of a newspaper to see why such publications are allocated most of their space to the sports which have more spectators commercially and less are attended to noncommercial sports. Theberge and Cronk are paid to this issue that why newspapers cover the men's sport at the expense of virtual exclusion of women's sport. These general questions led to research foundation of Lowes and Theberge and Cronk. Are adopted the ways of study of the journalistic routine affairs which was used in the previous studies of media with success. Their research questions are found towards the impact of organizational structure on the media content and or reproduction of the dominant social values like the priority of commercial and patriarchal values in the mediated sport. The studies related to the production in sport-media which is done lately has noticed its focus point to the impact of globalization on the difficult process of production an event from the immediate effects of routine and under time pressure affairs.

Considering that nearly all done researches in this field only have sufficed to check the appearance of programs and have been ignored other aspects of channels and sport programs, the researcher in this research tries with review content, the structure of programs and the functional role of sport channel programs and with offering the results to be able is taken a step in order to further enrich of Iran sport channel and meet the needs of the audience. With all the interpretations and conclusions which was presented from the research was conducted, here this question arises how is the quality content of broadcast programs from the sport channel based on the mentioned variables which will discuss about them in the following and what difference is exist in the pattern broadcast of this channel. This research results can help to official policy of national media and sport channels in addition to costs which do in order to set up dedicated channels including sport channel can achieve the contained objectives in the mission of these channels and this research can be useful along with the other done researches in the development of strategies of internal sport channel.

\section{Methodology}

The method of this research in terms of strategy is descriptive, in terms of performance path is content analysis, based on purpose is practical, in terms of time is present, in terms of data collection method is attributive and in terms of time period is sectional. The data collection tool in this research is the encoded sheet of researcher which is paid to investigate the content, structure and functional roles in the programs of sport channels. The objectivity coefficient of encoded form is obtained $89 \%$ by Kappa. It should be noted that in this research the encoded form is paid to examine and measure the variables of broadcasting hours, time broadcasting, how to play (live \& production), the type of program (match, commentary and analysis, report, documentary, education, discussion and combined programs), day of play, sexuality, type of sport programs (the team and single), the name of sport fields, the functional roles of sport programs (informative, educational, social participation, build culture and synthetic), four components of sport (championship, professional, educative and universal), age coverage of audiences (the programs is for what age group), the background of program (event related or process related), geographic coverage (is sport programs limited to a certain area like national and continental League and or universality of programs like World Cup or World Championship), repetitive or non-repetitive of programs and the basis of programs (talk and non-talk of programs). The statistic society in this 
research are included all of the programs of Iran sport channel. Accordingly the research community in this section is included that the total daily conductors of this channel will be during one season, then one month and finally one week. The statistic sample of research was also selected as cluster-random among the 13 weeks. Due to the sensitivity and importance of this issue on one hand and the extent and diversity of sport channel programs, in this research the programs are examined for 15 days (instead of one week) which is examined in the first half of April. The descriptive statistics like percentages, charts, mean and frequencies is used to describe the examined variables of sport channel. Also the statistics tests of Chi-square coefficient $\left(\mathrm{Xi}^{2}\right)$ is used to analyze the hypothesis. In the data analysis is used SPSS software.

\section{Findings}

In this section the collected data after analysis are shown in the form of tables and graphs and findings are provided. In table 1 , the frequency of programs is provided in the examined sport channel.

As the results in table 1 shows most of the sport programs of sport channel are composed of non-live programs $75.4 \%$ and the live programs assigns $24.6 \%$ of programs to itself.

As the results of table 2 shows the most frequency among the sport programs is related to sport competitions of different fields with $45 \%$. Also the lowest level of programs is related to entertainment programs with $0 \%$ and interpretation and analysis programs with $1.9 \%$.

The table 3 shows that $42.4 \%$ of programs is peculi ar for men's sport and only $0.3 \%$ of programs is assigned to women's sport. Also $57.3 \%$ of programs is without emphasis on gender (like sport news, sport pictures, interpretation and analysis and discussions).

In table 4 is provided the reflected sport fields of the sport channel separately.

According to the obtained results, football sport field with frequency percentage of $14.9 \%$ is assigned the most level of broadcast and theme of programs to itself. After football, the car riding field with $11.3 \%$ is placed in second place and then are placed the fields such as climbing, programs with a focus on wellness. Among the broad cast sport fields riding bike, tennis table and sailing with $0.3 \%$ are assigned the lowest level to themselves. Also the programs which their focus is more than one sport field also with $32 \%$ are assigned a significant part of daily broadcast tables to themselves and there was no base sport fields like track and field, swim and gymnastic separately in the broadcast tables (in some combined programs was displayed these three sport fields).

In table 5 is provided the content analysis of programs based on the functional roles and the covering of four components of sport separately.

According to obtained results in the

Table 1. The frequently distribution of programs based on type of broadcast

\begin{tabular}{lcc}
\hline $\begin{array}{l}\text { Frequency } \\
\text { percentage }\end{array}$ & Frequency & $\begin{array}{c}\text { Type of } \\
\text { broadcast }\end{array}$ \\
\hline $24 / 6$ & 76 & Live \\
$75 / 7$ & 233 & Non-live \\
100 & 309 & Total \\
\hline
\end{tabular}

Table 2. the separation of type of broadcasting programs in the sport channel in the examined time limit

Frequency Frequency Type of program percentage

\begin{tabular}{|c|c|c|}
\hline 45 & 139 & Matches \\
\hline $1 / 9$ & 6 & $\begin{array}{l}\text { interpretation and analysis } \\
\text { programs }\end{array}$ \\
\hline $12 / 6$ & 39 & News \\
\hline $19 / 1$ & 59 & Documentary \\
\hline $8 / 4$ & 26 & Sport training \\
\hline $7 / 4$ & 23 & Pictures and videos of sport \\
\hline 0 & 0 & Entertainment programs \\
\hline $3 / 6$ & 11 & Conversation \\
\hline $1 / 9$ & 6 & $\begin{array}{l}\text { The combination of several } \\
\text { programs }\end{array}$ \\
\hline 100 & 309 & Total \\
\hline
\end{tabular}

Table 3. Programs frequency based on coverage sexuality

\begin{tabular}{lcl}
\hline $\begin{array}{l}\text { Frequency } \\
\text { percentage }\end{array}$ & Frequency & $\begin{array}{l}\text { Type of } \\
\text { broadcast }\end{array}$ \\
\hline $4 / 42$ & 131 & Man \\
$3 / 0$ & 1 & Woman \\
$3 / 57$ & 177 & $\begin{array}{l}\text { Without emphasis on } \\
\text { gender }\end{array}$ \\
100 & 309 & Total \\
\hline
\end{tabular}


functional roles variable the informative variable with $23.6 \%$ is assigned the most level of programs to itself and build culture with $3.6 \%$ is assigned the lowest level of programs to itself and programs with the combination of roles is formed $48.9 \%$ of programs. In the four components of sport variable, the professional sport with $38.2 \%$ of programs is assigned the most level of programs to itself and sport education variable with $0.6 \%$ is assigned the lowest level of programs to itself. . In the four components of sport variable, the programs which was displayed in them the combination of components is assigned $30.7 \%$ of programs to itself.

Table 4. The frequency of displayed sport fields from the sport channel during search

\begin{tabular}{|c|c|c|c|c|c|}
\hline Sport field & Frequency & $\begin{array}{l}\text { Frequency } \\
\text { percentage }\end{array}$ & Sport field & Frequency & $\begin{array}{l}\text { Frequency } \\
\text { percentage }\end{array}$ \\
\hline Football & 46 & $5 / 14$ & Riding bike & 1 & $3 / 0$ \\
\hline Volleyball & 20 & $5 / 6$ & Motor riding & 3 & 1 \\
\hline Basketball & 14 & $4 / 5$ & $\begin{array}{l}\text { Traditional, } \\
\text { native and local } \\
\text { sports and } \\
\text { games }\end{array}$ & 7 & $3 / 2$ \\
\hline Baseball & 1 & $3 / 0$ & $\begin{array}{l}\text { Sport activities } \\
\text { related to health } \\
\text { and wellness }\end{array}$ & 22 & $1 / 7$ \\
\hline Handball & 15 & $9 / 4$ & Climbing & 22 & $1 / 7$ \\
\hline Earthy tennis & 4 & $3 / 1$ & Sailing & 1 & $3 / 0$ \\
\hline Tennis Table & 1 & $3 / 0$ & Ski & 1 & $3 / 0$ \\
\hline Badminton & 1 & $3 / 0$ & Wrestling & 12 & $9 / 3$ \\
\hline $\begin{array}{l}\text { Epic sports } \\
\text { (Wusho, Muytay } \\
\text { and so on) }\end{array}$ & 1 & $3 / 0$ & Taekwondo & 3 & 1 \\
\hline Car racing & 35 & $3 / 11$ & $\begin{array}{l}\text { The programs } \\
\text { which is shown } \\
\text { several fields in it }\end{array}$ & 99 & 32 \\
\hline
\end{tabular}

Table 5. The frequency of programs based on the based on the functional roles and the covering of four components of sport

The functional roles of sport programs The covering of four components of sport Variable in the sport programs

\begin{tabular}{|c|c|c|c|c|c|c|c|c|c|c|}
\hline 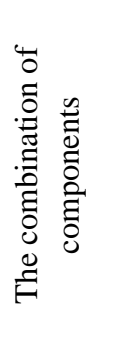 & $\frac{.}{\bar{\Xi}}$ & 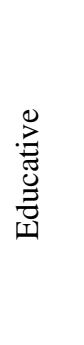 & 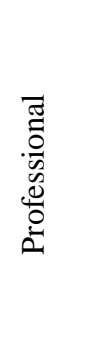 & 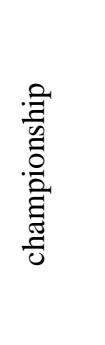 & 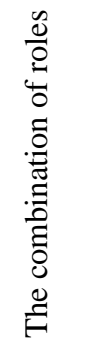 & 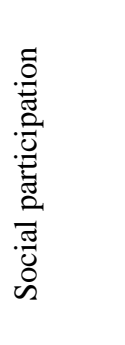 & 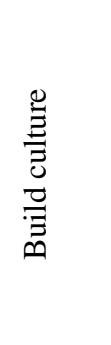 & 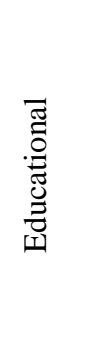 & 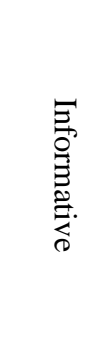 & 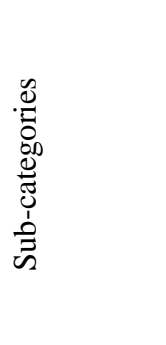 \\
\hline 95 & 50 & 2 & 118 & 44 & 151 & 36 & 38 & 11 & 73 & Frequency \\
\hline$\% 30 / 7$ & $\% 16 / 3$ & $\begin{array}{c}0 / 6 \\
\%\end{array}$ & $\% 38 / 2$ & $\% 14 / 2$ & $\% 48 / 9$ & $\% 11 / 7$ & $\% 12 / 3$ & $\% 3 / 6$ & $\begin{array}{c}23 / 6 \\
\%\end{array}$ & $\begin{array}{l}\text { Frequency } \\
\text { percentage }\end{array}$ \\
\hline
\end{tabular}


In the table 6 is provided the investigation of frequency of variables of production field, the program status according to repeat, geographical coverage, production-oriented programs, the age coverage of program and the reflection level of team and single sports.

From the total examined programs $87.7 \%$ of programs are composed of talk-orients programs and $13.3 \%$ of programs are composed of non-talkoriented programs. In relation to repeat programs variable $86.7 \%$ of the available programs in the broadcast tables were non-repetitive programs and $14.3 \%$ were repetitive programs. In relation to geographic belongs of programs $71.5 \%$ of sport programs were related to around the world (like
World Cup and World League and so on). Also $22.3 \%$ of programs are related to the Asia continent events. In relation to the production axis of programs $57.3 \%$ of them are composed of processoriented programs and $46.3 \%$ of them are composed of event-oriented programs. In the age variable the most level of programs were programs which are related to the all ages and the sport programs relevant and specific to the elderly, childes and adolescents and youths was very low. Finally, the analysis of reflection the team and single sports shows that $34.6 \%$ of programs are composed of single sports and $31.7 \%$ of programs are composed of team sports.

The results in table 7 which are paid to

Table 6. To investigate frequency of variables of production field, the program status according to repeat, geographical coverage, production-oriented programs, the age coverage of programs and the reflection level of team and single sports

\begin{tabular}{llll}
\hline Frequency percentage & Frequency & Sub-categories & Variable \\
\hline $3 / 12$ & 38 & Talk-oriented program & Production field \\
$7 / 87$ & 271 & Non-talk-oriented program & \\
$7 / 86$ & 268 & Non-repetitive & Repetition \\
$3 / 13$ & 41 & Repetitive & Geographical coverage \\
$3 / 22$ & 69 & Asia & \\
$6 / 1$ & 5 & Europe & \\
$5 / 4$ & 14 & Africa & \\
14 & 5.4 & America & Production axis \\
$5 / 71$ & 221 & Programs and events related & \\
& & to around the world & \\
$3 / 46$ & 143 & Event-oriented & \\
$7 / 53$ & 166 & Process-oriented & \\
6 & 2 & Childs and adolescents & \\
$0 / 6$ & 2 & Youth & \\
$1 / 9$ & 28 & Adults & The reflection of team and single sports \\
0 & 0 & Seniors & \\
$6 / 89$ & 277 & All ages & \\
$7 / 31$ & 98 & Team & Single \\
$6 / 34$ & 107 & Both types & \\
$7 / 33$ & 104 &
\end{tabular}

Table 7. The comparing of sexuality, functional roles, four components of sport, production axis and production background variables of sport programs

\begin{tabular}{lccc}
\hline The examined variable & $\begin{array}{c}\text { The statistics } \\
\text { level of Chi2 }\end{array}$ & $\begin{array}{c}\text { Freedom } \\
\text { degree }\end{array}$ & Sig \\
\hline Programs gender & $78 / 161$ & 2 & $0001 / 0$ \\
The functional roles of programs & $47 / 192$ & 4 & $0001 / 0$ \\
The reflection of four components of sport & $18 / 234$ & 4 & $0001 / 0$ \\
Production axis (be event-oriented or process-oriented) & $1 / 71$ & 1 & $191 / 0$ \\
The production background (talk-oriented or non-talk-oriented) & $69 / 175$ & 1 & $0001 / 0$ \\
& & & \\
\hline
\end{tabular}


compare the sexuality, functional roles, four components of sport, production background and production axis variables of sport programs in the examined sport channel is indicated this subject that there is a significant difference in the four examined variables in the sport program but in the production axis variable of sport programs (eventoriented or process-oriented of programs) there isn't a significant difference in the examined programs. The statistics level of Chi2 and the significant level in the variables of sexuality $\left(\mathrm{x}^{2}=\right.$ 161.78 and sig $=0.0001)$, functional roles $\left({ }^{x 2}=192.47\right.$ and sig $=0.001$ ), reflection of four components of sport $\left({ }^{\times 2}=134.18\right.$ and sig $\left.=0.001\right)$ and production background of programs $\left({ }^{\times 2}=175.69\right.$ and sig $\left.=0.001\right)$ have sign of a significant difference in the $(\mathrm{p}<0.01)$ level in the all above variables in the sport program, therefore and with relying on the obtained results the suppose of researcher is confirmed based on the availability of difference in the mentioned variables among the examined channels and there was no enough reasons for confirmation of null hypothesis. In relation to production axis of programs (event-oriented or process-oriented of sport programs) the amounts of statistics of Chi2 and the significant $\left({ }^{\mathrm{x} 2}=1.71\right.$ and sig $\left.=0.191\right)$ in the $(p<0.05)$ hasn't a significant difference in the programs based on event-oriented and processoriented.

\section{DISCUSSION}

The aim of this research was the analysis of content, programs structure and functional roles of TV sports. As the results of table 1 shows most of the sport programs of sport channel are composed of non-live programs with $75.4 \%$ and live programs are assigned $24.6 \%$ of programs to themselves. The results show that the most frequency among the sport programs is related to sport championship of different fields with $45 \%$. Also the lowest level of programs was related to entertainment programs with $0 \%$ and interpretation and analysis programs with $1.9 \%$. $42.4 \%$ of programs is assigned to men's sport and only 0.3 $\%$ of programs is assigned to women's sports. Also $57.3 \%$ of programs is without emphasis on gender (like sport news, sport pictures, interpretation and analysis and conversation). According to the obtained results football sport field with frequency percentage of $14.5 \%$ is assigned the most level of broadcast and programs themes to itself. Among the broadcasted sport fields bike riding, Table tennis and sailing with $0.3 \%$ are assigned the lowest level to themselves. In the functional roles variable, the informative variable with $23.6 \%$ is assigned the most level of programs to itself and build culture with $3.6 \%$ is assigned the lowest level of programs to itself. In four components of sport variable, the professional sport $38.2 \%$ was assigned the most level of programs to itself and educated sport with $0.6 \%$ is assigned the lowest level of programs to itself. Of the all studied programs, $87.7 \%$ of programs are composed of talkoriented programs and $13.3 \%$ of programs are composed of non-talk-oriented programs. In relation to repeat programs variable, $86.7 \%$ of the programs in the broadcast tables were nomrepetitive programs and $14.3 \%$ were repetitive programs. In relation to geographical belong of programs, $71.5 \%$ of sport programs were related to the around of the world (like World Cup, World League and so on). Also 22.3\% of programs were related to the events of Asia continent. In relation to production axis of programs, $53.7 \%$ of them were composed of process-oriented programs and $46.3 \%$ of them were composed of event-oriented programs. The investigation of results in the gender variable shows that the comparison between the content of examined channels based on the gender, functional roles, four components and the production background of sport programs shows that there is a significant difference in the $(p<0.01)$ in the mentioned components in the broadcasted programs from sport channel, but in the production axis variable there isn't a significant difference among the studied programs. In the gender variable, the results of this research have consistency and compliance with researches of Nazarveisi, Karami, Ghasemi and Nemati Anaraki and Ghasemi, Farahani Shakeri and Hosseini which all of the mentioned researches have story of allocating a small share or non-allocated of women's sport programs in the studied broadcasted tables. From the reasons of consistency of mentioned researches can benamed the proximity of performance time of all mentioned researches and the implementation of all researches in the sport channels and programs reflected from internal channels and TVs. In the four components of sport, the results of this research is consistent 
with the research of Shokrani and Aghapour which during a research concluded that the time period of broadcasting of programs related to public sport is low in compare with professional and championship sport. The broadcasting period time the championship sport programs is long in TV. Broadcasting time of programs related to base sport is very low in TV. The broadcasting time of the programs related to women's sport is very low in TV. Also is consistent with researches of Askari, Ghasemi and Keshkar and Molaee and Emami. The reason for conformity in the results can be known the channels' use of professional and championship sport programs and events in attracting more audiences which is arising from the policies of these channels. Of course, in the broadcasting programs tables, the use of charming and pleasant sport programs of the people which is placed among the championship and professional sport programs is more concerned. In this regard Lim's research shows that the events and sports which are along with more charming and violence have more viewers and have a rapid development in the world. In relation to the production background of TV programs variable in terms of focused on the talk-oriented programs, the result of this research is consistent with the research of Askari, Ghasemi and Keshkar.

Depending on what is in the introduction in relation with the mutual effect of sport in media and media in sport development, the programs special to children and adolescents (the championship and educational) will not unpleasant. Because on one hand the reflection of news and events of this age group which are in the basic level will fill a background and interest to participate of this class in sport and in the other hand the blank space of public and educative sport (schools) in the broadcasting tables of sort channel. The point which is seen lower in the studied broadcasting tables was the blank space of basic sports (the events and programs with thematic axis of these fields) like track and field, swim and gymnastic and as provided in the various sources are as foundation for comprehensive development of sport which the media reflection of these fields can bear a little burden of develop of these sport fields. In general look and in examines variables in this research and earlier researches isn't observed the balance in the allocation and reflection programs in the broadcasting programs of Iran sport channel which demands the need to review and consider of topics which is raised which can be reached to the promotion of the position of sport channel among the audiences.

\section{REFERENCE}

1. Shokrani, Ebrahim \& Agha pour, Seyed Mehdi To investigate and analyze the content of sport programs of Islamic Republic of Iran Broadcasting. The contemporary researches in the sport management, 2014; 4(8): 81-92.

2. Shokrani, Ebrahim. The assessment of sport status in the sound and vision. Master thesis, Tehran Payam Noor University, 2007.

3. Sadeghi, Reza, Keshkar, Sara \& Ghasemi, Hamid The role of modern and traditional media in the promotion of popularity of sport events in the expert's opinion and to provide solution. First national conference of management organization of sport events, Isfahan Payam Noor University, 2013.

4. Askari, Bahman, Ghasemi, Hamid \& Keshkar, Sara., The study of quantitative content of sport programs of cannel three. Research communication, 2011; 18(4), consecutive 68, 135-151.

5. Askari, Bahman, Ghasemi, Hamid \& Keshkar, Sara). The study of content conductors of sport programs of youth and sport channel (channel three). Sixth national conference of students of physical education and sports science, Tehran University, 2012.

6. Ghasemi, Hamid \& Keshkar, Sara. The rule of trust to the sport media in its effectiveness level on the student athletes. Journal of Sports Science Research, 2011; 2(5): 75-89.

7. Ghasemi, Hamid., The analysis of the content of sport newspapers with emphasis on the coverage of sport components in the final semester of 2009. The second national specialist conference of the sport management, Shahrod industrial University, 2012.

8. Ghasemi, Hamid, Farhani, Abolfazl, Shakermi, Zahra \& Hosseini, Seyed Saeed. The content analysis of sport programs of broadcasting provinces with emphasis on the coverage of women's sport. Communication management in the sport media, 2013; 1(2): 23-30.

9. Ghasemi, Hamid, Karami, Abdollah \& Sadeghi, Farshad., The status of the TV coverage of sport tournaments in the vision channels from the perspective of media professionals of country. The applied research in the sport management, 
2013; 2(4): 43-54.

10. Karami, Abdollah., The content analysis of sport programs in Iran TV channels. Master thesis, Azad University of Central Tehran Branch, 2012.

11. Karami, Abdollah, Ghasemi, Hamid \& Nemati Anaraki, Davood. The content analysis of sport programs of the country TV channels with the approach of women's sport. Research-scientific journal of communication research, 2011; 19 (1): 135-155.

12. Mahdavian Mashhadi, Maryam. The comparing of existing and desirable situation of radio, TV, press role in the women's sport in the perspective of experts. Research-scientific journal of communication research, nineteenth research, 2012; 69.

13. Al Jazeera Sport teams up with OMD and TBWARAAD: http://www.mediame.com/en/ new s / announcement/a l_ jazeera sport_teams_omd_and_tbwaraad. 04/29/2013

14. Curran, J., Media and power. London: Routledge. Holland, P. (2000). The Television Handbook. First Published, Landon: Routledge, 2002.

15. Lawrence A. Wenner., Mediasport. Psychology Press, Social Science, 1998.

16. Louise Gee, B., Sport media decision-making in France: How they choose what we get to see and read. At Massey University, Manawatu
New Zealand, 2009.

17. Lull, J., Media, communication, culture. Cambridge: Polity Press, 2000.

18. McCombs, M., Agenda setting function of mass media. Public Relations Review, 1977; 3(4): 8995.

19. Rowe, David. Sport, Culture and the Media. Mc Graw Hill Education, Second edition, 2004.

20. Van Puymbroeck Marieke., Does the Media Impact Athletic Performance? University of Illinois, 2006.

21. Wu, P., Sport and the media. In P. Craig \& Beedie (Eds), sport sociology. Exeter: Learning Matters. 2008; 148-163

22. Zhang, J, J. Smith, D, W., Impact of Broadcasting on Attendance of Professional Basketball Games. Sport marketing quarterly. 1997; 6(1): 1997.

23. Kang, J., Lim, C., Lee, W. \& Pedersen, P.M., Balancing promotion and social responsibility by sport management and media professionals: Investigating the potentially negative influence of viewing mediated sport violence. The 18th Annual European Sport Management Conference: European Association for Sport Management (EASM). Prague, Czech Republic, 2010. 